\title{
ARTICLE
}

\section{Interruption of continuous opioid exposure exacerbates drug-evoked adaptations in the mesolimbic dopamine system}

\author{
Emilia M. Lefevre (iD) ${ }^{1}$, Marc T. Pisansky (iD) ${ }^{1}$, Carlee Toddes ${ }^{2}$, Federico Baruffaldi ${ }^{3}$, Marco Pravetoni ${ }^{3,4,5,6}$, Lin Tian $^{7}$, \\ Thomas J. Y. Kono (iD ${ }^{8}$ and Patrick E. Rothwell (iD ${ }^{1}$
}

\begin{abstract}
Drug-evoked adaptations in the mesolimbic dopamine system are postulated to drive opioid abuse and addiction. These adaptations vary in magnitude and direction following different patterns of opioid exposure, but few studies have systematically manipulated the pattern of opioid administration while measuring neurobiological and behavioral impact. We exposed male and female mice to morphine for one week, with administration patterns that were either intermittent (daily injections) or continuous (osmotic minipump infusion). We then interrupted continuous morphine exposure with either naloxone-precipitated or spontaneous withdrawal. Continuous morphine exposure caused tolerance to the psychomotor-activating effects of morphine, whereas both intermittent and interrupted morphine exposure caused long-lasting psychomotor sensitization. Given links between locomotor sensitization and mesolimbic dopamine signaling, we used fiber photometry and a genetically encoded dopamine sensor to conduct longitudinal measurements of dopamine dynamics in the nucleus accumbens. Locomotor sensitization caused by interrupted morphine exposure was accompanied by enhanced dopamine signaling in the nucleus accumbens. To further assess downstream consequences on striatal gene expression, we used next-generation RNA sequencing to perform genome-wide transcriptional profiling in the nucleus accumbens and dorsal striatum. The interruption of continuous morphine exposure exacerbated drug-evoked transcriptional changes in both nucleus accumbens and dorsal striatum, dramatically increasing differential gene expression and engaging unique signaling pathways. Our study indicates that opioid-evoked adaptations in brain function and behavior are critically dependent on the pattern of drug administration, and exacerbated by interruption of continuous exposure. Maintaining continuity of chronic opioid administration may, therefore, represent a strategy to minimize iatrogenic effects on brain reward circuits.
\end{abstract}

Neuropsychopharmacology (2020) 45:1781-1792; https://doi.org/10.1038/s41386-020-0643-x

\section{INTRODUCTION}

Opioid analgesics taken for pain relief also activate opioid receptors in the mesolimbic dopamine system, including the ventral tegmental area (VTA) and nucleus accumbens [1, 2]. Stimulation of these receptors is positively reinforcing $[3,4]$ and enhances mesolimbic dopamine release in rodents $[5,6]$, though this latter effect has been difficult to detect in humans $[7,8]$. While dopamine manipulations have mixed effects on acute opioid reward [6, 9], chronic opioid exposure produces transcriptional and epigenetic changes in the nucleus accumbens, leading to structural and functional circuit remodeling that are hypothesized to promote addiction and vulnerability to relapse [10-12]. Prevention strategies that minimize these iatrogenic effects might facilitate safer opioid use for clinical indications [13].

Different patterns of drug exposure produce diverse effects on mesolimbic dopamine function and addiction-related behavior (e.g., refs. [14-25]). Decreased sensitivity (i.e., tolerance) is typically reported after relatively continuous patterns of opioid administration, whereas increased sensitivity (i.e., sensitization) is commonly observed after more intermittent patterns of opioid exposure [26-28]. These divergent effects of continuous and intermittent opioid exposure have been reported for mesolimbic dopamine release [29-31], drug reward [32-38], and psychomotor activation [39-43]. Given the variable pharmacokinetics of prescription opioid formulations purported to provide continuous action [44], it is critical to understand how the pattern of opioid exposure shapes adaptations in the mesolimbic dopamine system, in order to minimize/prevent adaptations that promote opioid abuse and addiction. Based on prior literature [45-48], our guiding hypothesis was that maintaining the continuity of opioid exposure reduces iatrogenic effects, by preventing withdrawal caused by fluctuating drug levels.

To test this hypothesis, we first replicated prior reports that intermittent morphine injections produce psychomotor sensitization, whereas continuous morphine infusion produces psychomotor tolerance. However, this comparison was confounded by large differences in pharmacokinetic variables like cumulative dose and peak drug level. We, therefore, adopted a pharmacodynamic strategy of interrupting continuous morphine administration with daily injections of an opioid receptor antagonist, to precipitate a

\footnotetext{
${ }^{1}$ Department of Neuroscience, University of Minnesota, Minneapolis, MN, USA; ${ }^{2}$ Graduate Program in Neuroscience, University of Minnesota, Minneapolis, MN, USA; ${ }^{3}$ Hennepin Healthcare Research Institute, Minneapolis, MN, USA; ${ }^{4}$ Department of Pharmacology, University of Minnesota, Minneapolis, MN, USA; ${ }^{5}$ Department of Medicine, University of

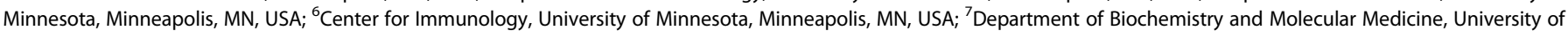
California, Davis, CA, USA and ${ }^{8}$ Minnesota Supercomputing Institute, University of Minnesota, Minneapolis, MN, USA Correspondence: Patrick E. Rothwell (rothwell@umn.edu)
}

Received: 3 July 2019 Revised: 10 February 2020 Accepted: 13 February 2020

Published online: 20 February 2020 
state of withdrawal. This manipulation provided control over pharmacokinetic variables, and caused a reversal of psychomotor adaptation from tolerance to sensitization. This switch to locomotor sensitization was accompanied by enhanced dopamine signaling in the nucleus accumbens, as well as changes in striatal gene expression measured with next-generation RNA sequencing. Together, our data suggest sensitization of the mesolimbic dopamine system can be minimized by maintaining the continuity of opioid exposure during chronic treatment, highlighting an actionable prevention strategy to reduce opioid abuse.

\section{MATERIALS AND METHODS}

Subjects

Male and female C57BL/6J mice, mu opioid receptor (Oprm1) knockout mice [49], and dopamine transporter (DAT)-IRES-Cre knock-in mice [50] were obtained from The Jackson Laboratory or bred in-house. Experimental procedures were approved by the Institutional Animal Care and Use Committee of the University of Minnesota. For additional details, see Supplementary Information.

\section{Drug exposure}

Morphine hydrochloride (Mallinckrodt) was dissolved in sterile saline $(0.9 \%)$, and delivered subcutaneously by bolus injection $(5 \mathrm{~mL} / \mathrm{kg})$, continuous infusion using osmotic minipumps (Alzet Model 2001), or programmed infusion using miniaturized mechanical pumps (iPrecio SMP-300). For additional details, see Supplementary Information. To interrupt continuous morphine exposure, we injected mice with saline or naloxone $(0.1-10 \mathrm{mg} / \mathrm{kg}$, s.c.) twice per day, with injections separated by a period of $2 \mathrm{~h}$ [51]. Behavioral assessments were performed prior to naloxone injection on the first day of morphine exposure, and again $24 \mathrm{~h}$ after the final naloxone injection.

\section{Behavioral and pharmacokinetic assessments}

We tested open-field locomotor activity in a clear plexiglass arena (ENV-510, Med Associates) housed within a sound-attenuating chamber. Thermal antinociception was tested on a $55^{\circ} \mathrm{C}$ hot plate (IITC Life Scientific). Serum morphine were measured by gas chromatography coupled with mass spectrometry as previously described [52, 53]. For additional details, see Supplementary Information.

\section{Stereotaxic surgery and fiber photometry}

Intracranial virus injection and optic fiber implantation were performed as previously described [54]. Continuous fiber photometry recordings were conducted in the open-field chambers described above, for $30 \mathrm{~min}$ before and after naloxone injection on Days 1 and 7, with spontaneous fluorescent transient events detected as previously described [55]. On challenge days, recordings were conducted for $30 \mathrm{~min}$ before and after injection of morphine or fentanyl. The average fluorescent signal following challenge injection was compared with baseline prior to injection. For additional details, see Supplementary Information.

Gene expression and RNA sequencing

RNA sequencing was performed using male mice to minimize variability, while equal numbers of both sexes were used in all other experiments, including targeted gene expression analysis with qPCR. Following six days of chronic treatment, we rapidly removed brains under isoflurane anesthesia, and dissected bilateral nucleus accumbens (core and shell) and dorsal striatum (caudate-putamen) on ice. For additional details, see Supplementary Information.

Statistical analyses

Analysis of variance (ANOVA) was conducted in IBM SPSS Statistics v24, with details provided in Supplementary Information. In the text, we report significant effects that are critical for data interpretation, but comprehensive reporting of all main effects and interactions from ANOVA models can be found in Table S2. Significant simple effects within group are indicated by a hash (\#) to the right of group data, while significant simple effects or posthoc tests between groups are indicated by an asterisk ${ }^{*}$ ) above the data. All summary data are displayed as mean \pm SEM, with individual data points from male and female mice show $\bar{n}$ as closed and open symbols, respectively.

\section{RESULTS}

Behavioral effects of intermittent injection versus continuous infusion of morphine

To compare different patterns of opioid exposure, we first delivered morphine for one week by daily injection (Fig. 1a) or continuous infusion (Fig. 1e), and measured open field locomotor activity on the first and last day. Morphine caused a dosedependent increase in locomotion after both injection (Fig. 1b; main effect of Dose: $F_{4,62}=94.91, p<0.001$ ) and infusion (Fig. 1f; main effect of Dose: $F_{2,42}=40.83, p<0.001$ ). Daily injections caused psychomotor sensitization (Fig. 1c; Dose $\times$ Day interaction $\left.\mathrm{F}_{4,62}=46.84, p<0.001\right)$, whereas continuous infusion caused psychomotor tolerance, (Fig. 1g; Dose $\times$ Day interaction: $F_{2,42}=$ 8.94, $p=0.001$ ), while both exposure patterns caused antinociceptive tolerance (Fig. S1A, B). To examine the persistence of psychomotor adaptation, we challenged all groups with morphine injections 10 days after the end of chronic treatment. Psychomotor sensitization persisted during this challenge test (Fig. 1d; Pretreatment Dose $\times$ Challenge Dose interaction: $F_{9.92,153.75}=8.55$, $p<0.001$ ), whereas psychomotor tolerance did not persist (Fig. 1h; Pretreatment Dose $\times$ Challenge Dose interaction: $F_{5.75,51.73}=2.00$, $p=0.085$ ). The acute response to $6.32 \mathrm{mg} / \mathrm{kg}$ morphine (Fig. $1 \mathrm{~b}$ ) was greater than the challenge-response to this dose, likely reflecting novelty of the testing environment on Day 1.

These results show that different patterns of chronic morphine exposure cause similar adaptations in some behavioral responses (e.g., antinociception), but divergent adaptations in other behaviors (e.g., psychomotor activation), even when controlling for cumulative dose (e.g., $63.2 \mathrm{mg} / \mathrm{kg} /$ day). However, serum morphine levels were predictably higher after bolus injection versus continuous infusion (Fig. S1C, D), confounding the effect of exposure pattern with differences in the location/proportion of activated opioid receptors. This highlights the difficulty in simultaneously controlling multiple pharmacokinetic variables (e.g., cumulative dose and peak drug level) when comparing injections and infusions, motivating us to develop a model providing better control of these variables.

Behavioral effects of continuous versus interrupted morphine exposure

To interrupt continuous morphine infusion while controlling pharmacokinetic variables, we administered two daily naloxone injections separated by an interval of $2 \mathrm{~h}$ (Fig. 2a), as previously described [51]. We selected a high dose of naloxone $(10 \mathrm{mg} / \mathrm{kg})$ to fully interrupt activation of opioid receptors by morphine, as pilot studies showed this naloxone dose had more robust effects than lower doses (Fig. S2). The state of withdrawal precipitated by this dose of naloxone did not significantly change in severity across days (Fig. S3).

In open field tests of locomotor activity (Fig. 2b), control mice receiving continuous morphine exposure with saline injections displayed psychomotor tolerance. In contrast, mice receiving naloxone injections to interrupt morphine exposure displayed a switch to psychomotor sensitization (Morphine $\times$ Naloxone $\times$ Day interaction: $\left.F_{1,86}=10.32, p=0.002\right)$. The increase in locomotion on Day 7 versus Day 1 (Fig. 2c) was numerically larger in males $(71.64+$ $29.11 \mathrm{~m} / \mathrm{h}$ ) than in females $(17.12+12.25 \mathrm{~m} / \mathrm{h})$, although there were no statistically significant sex differences (Table S2). Serum morphine 
A

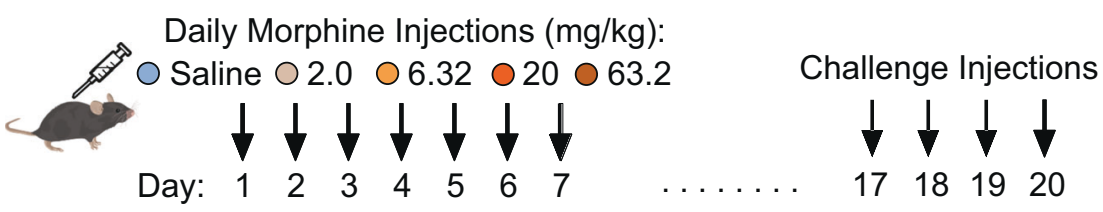

B

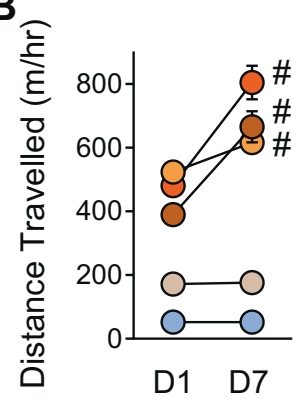

C

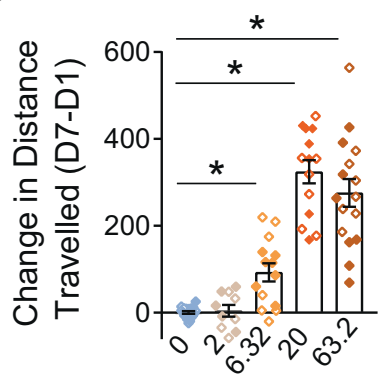

Pretreatment Dose
D

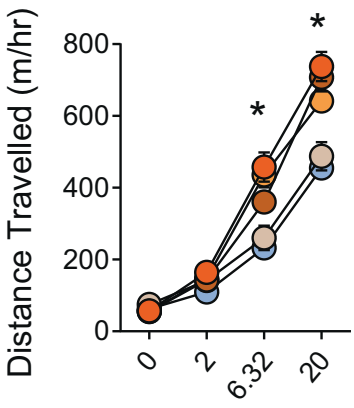

Challenge Dose $(\mathrm{mg} / \mathrm{kg})$

E

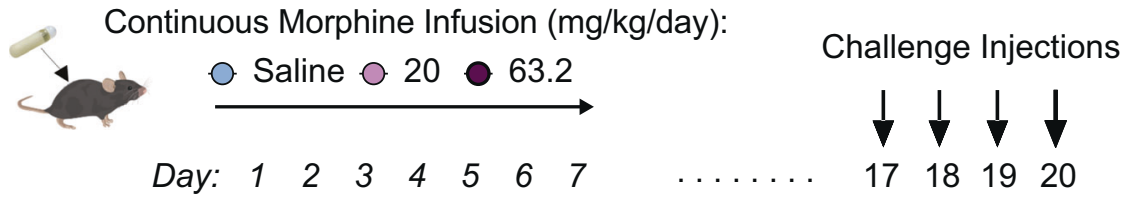

F

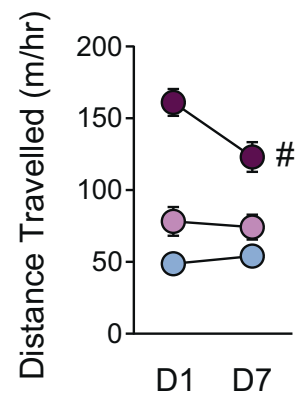

G

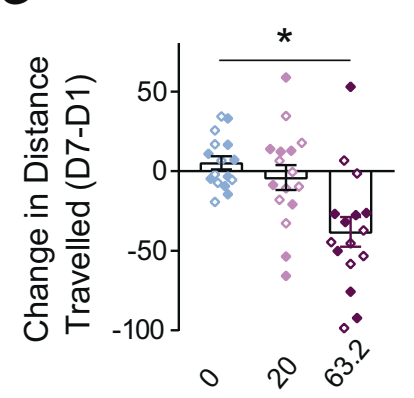

Pretreatment Dose
H

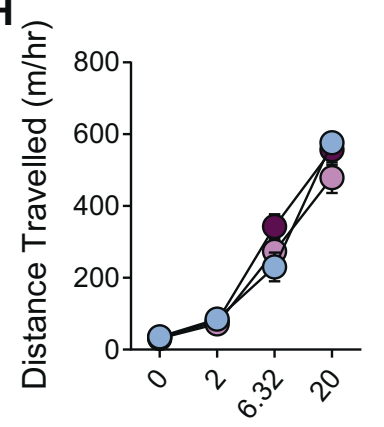

Challenge Dose $(\mathrm{mg} / \mathrm{kg})$

Fig. 1 Behavioral effects of intermittent injection versus continuous infusion of morphine. a Intermittent exposure consisted of seven daily injections of morphine, followed 10 days later by challenge with injection of escalating morphine doses ( $n=10-18 /$ group). b Locomotor activity after the first (D1) and last (D7) day of exposure. c Change in locomotor activity on D7 versus D1, depicted for individual mice at each dose. $\mathbf{d}$ Locomotor activity following challenge injections with ascending doses of morphine. e Continuous infusion of morphine via osmotic minipump for seven days, followed 10 days later by challenge with injection of escalating morphine doses ( $n=8 / \mathrm{group}$ ). f Locomotor activity on the first (D1) and last (D7) day of exposure. $\mathbf{g}$ Change in locomotor activity on D7 versus D1, depicted for individual mice at each dose. h Locomotor activity following challenge injections with ascending doses of morphine. All groups contained similar numbers of female mice (open symbols) and male mice (closed symbols); see Supplementary Table 2 for detailed statistical analyses. ${ }^{*} p<0.05$ between groups, LSD post-hoc test. ${ }^{\#} p<0.05$ for simple effect within group.

levels were equivalent between groups on the last day of chronic morphine exposure (Fig. 2d), and the development of antinociceptive tolerance was not affected by naloxone injections (Fig. 2e). Interrupted morphine exposure had no behavioral effect in mu opioid receptor knockout mice (Fig. S4), as previously reported for intermittent morphine injections $[49,56]$. Psychomotor tolerance was also reversed when continuous morphine administration was interrupted by periods of spontaneous withdrawal, using miniaturized programmable infusion pumps (Fig. S5).

Twenty-four hours after pump removal, locomotion was decreased in both morphine groups, reflecting a state of spontaneous withdrawal (Fig. 2f; main effect of Morphine: $F_{1,40}=$ 12.16, $p=0.001)$. The next day, all mice were challenged with injection of $2 \mathrm{mg} / \mathrm{kg}$ morphine (Fig. $2 \mathrm{~g}$ ). Psychomotor activation was blunted by previous exposure to continuous morphine, while sensitization persisted after interrupted morphine (Morphine $x$ Naloxone interaction: $\mathrm{F}_{1,64}=13.37, p=0.001$ ), suggesting both effects last for $48 \mathrm{~h}$ after chronic exposure. To map the persistence of these effects, a subset of mice continued receiving $2 \mathrm{mg} / \mathrm{kg}$ morphine challenges. We again observed a significant Morphine $x$ Naloxone interaction $\left(F_{1,39}=13.97, p<0.001\right)$, and thus separately analyzed the simple effect of morphine in each injection group. After interrupted morphine, psychomotor sensitization was evident in response to daily and weekly challenges, but then gradually diminished over subsequent months (Fig. 2h; main effect of Morphine: $F_{1,17}=14.21, p=0.002$ ). After continuous morphine, psychomotor tolerance dissipated almost immediately (Fig. 2i; main effect of Morphine: $F_{1,18}=1.23, p=0.28$ ). 


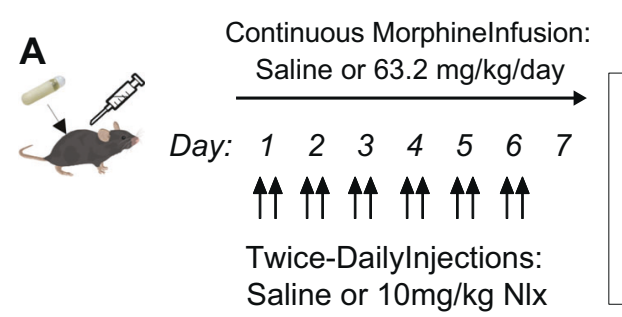

B

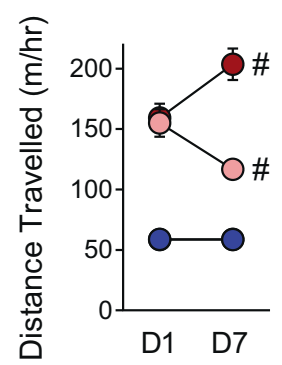

C

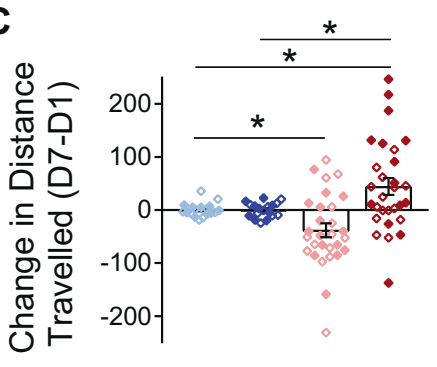

E

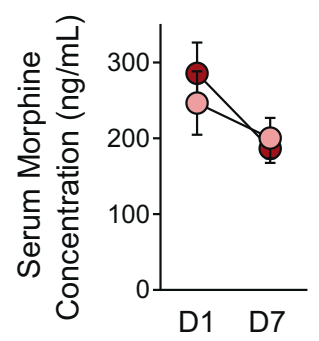

Pump Removal

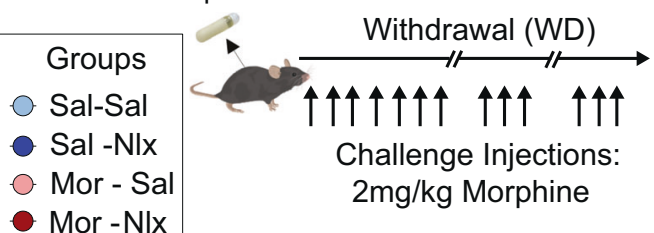

F

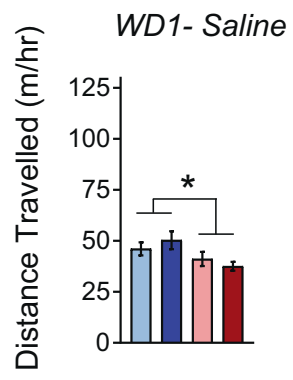

G

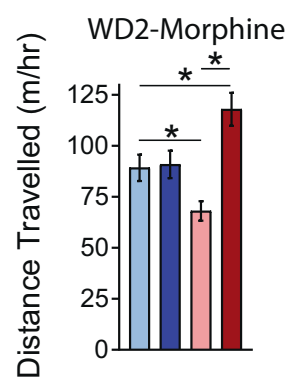

H

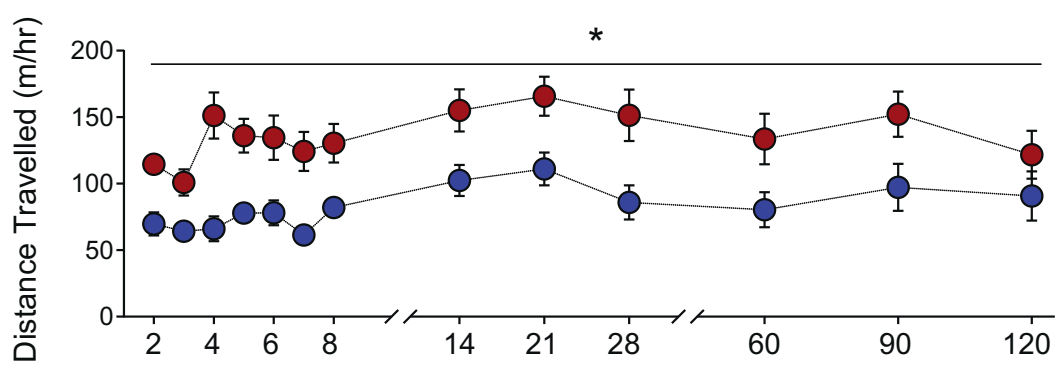

I

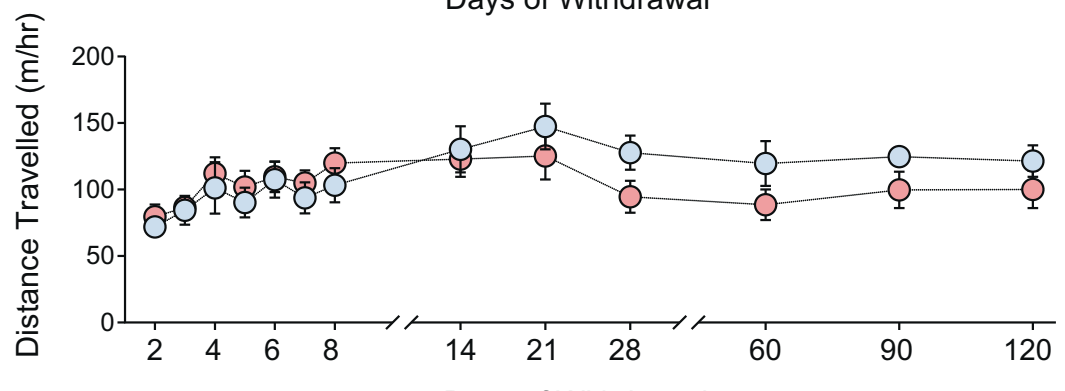

Days of Withdrawal

Fig. 2 Interruption of continuous morphine exposure with daily naloxone injections. a Continuous infusion of morphine or saline for one week, interrupted by twice-daily injections (separated by $2 \mathrm{~h}$ ) of saline or naloxone, followed by challenge injections of morphine ( $n=18-29$ / group). b Locomotor activity on the first (D1) and last (D7) day of exposure; note that data points from Sal-Sal and Sal-NIx groups are overlaid. c Change in locomotor activity on D7 versus D1, depicted for individual mice at each dose. ${ }^{*} p<0.05$ between groups, Tukey post-hoc test. d Serum morphine concentrations taken on D1 and D7 ( $n=5 /$ group). e Thermal antinociception on the hot plate, measured on D1 and D7. ${ }^{\#} p<0.05$ for simple effect within group. $\mathrm{f}$ Open field locomotor activity $24 \mathrm{~h}$ following pump removal. ${ }^{*} p<0.05$, main effect of Morphine. g Locomotor response to morphine challenge $48 \mathrm{~h}$ after pump removal. ${ }^{*} p<0.05$ between groups, LSD post-hoc test. $\mathbf{h}$, $\mathbf{i}$ Locomotor response to morphine challenges during extended withdrawal in groups that previously received daily injections of naloxone (h) or saline (i) $(n=12 /$ group). ${ }^{*} p<0.05$, main effect of morphine. All groups contained similar numbers of female mice (open symbols) and male mice (closed symbols); see Supplementary Table 2 for detailed statistical analyses. 
A

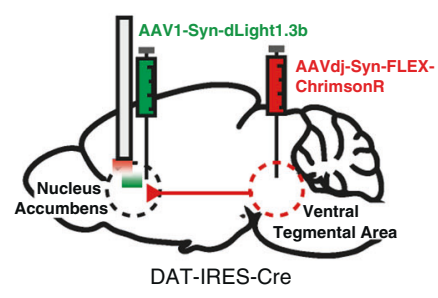

D

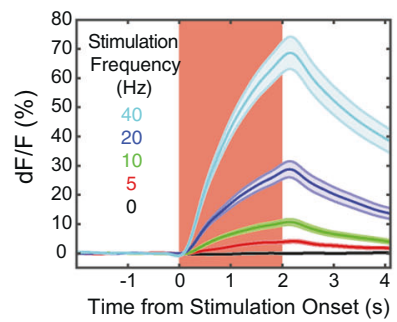

$\mathbf{F}$

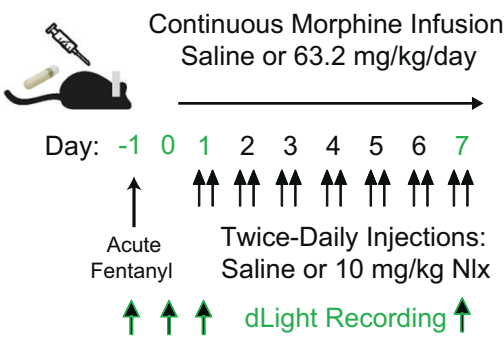

G

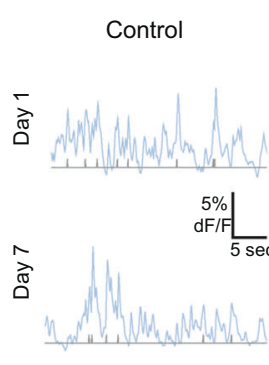

Continuous
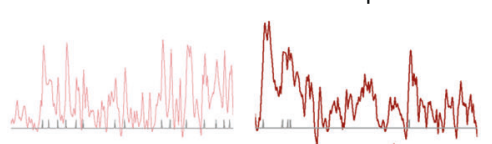

$\mathbf{H}$

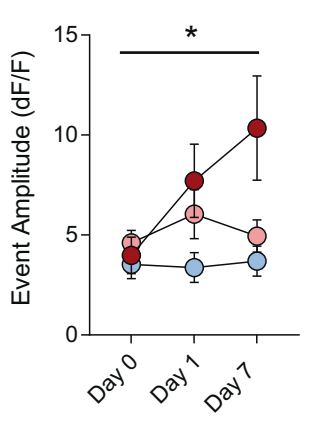

Withdrawal

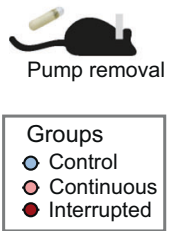

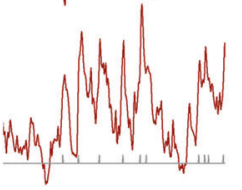

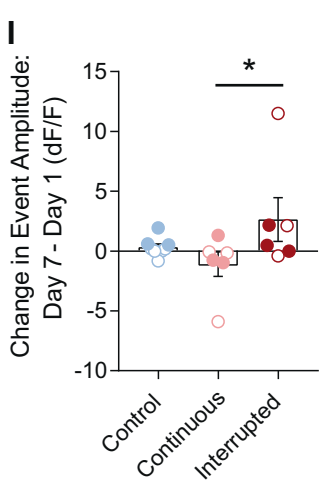

B

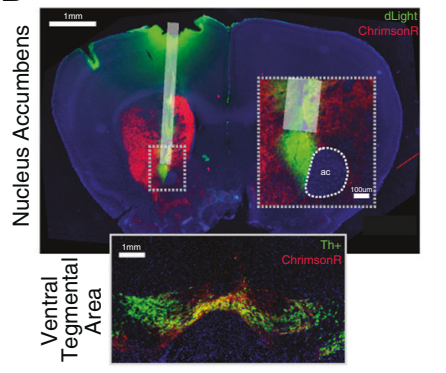

E

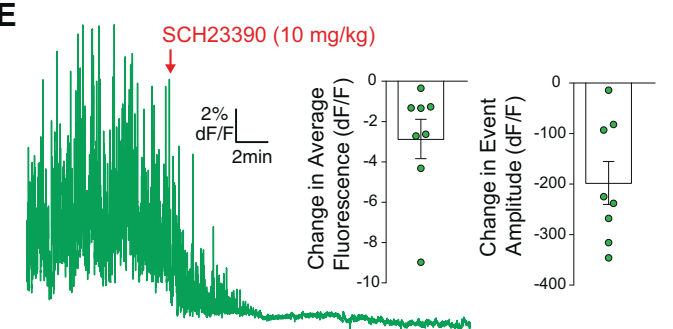

C

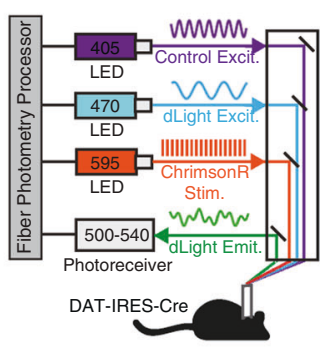

Challenge Injection

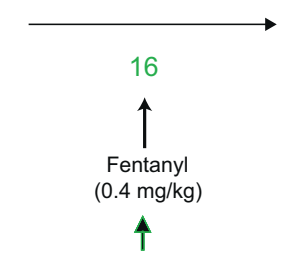

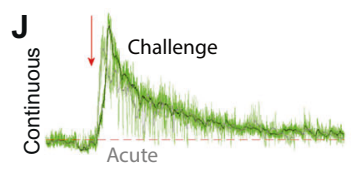
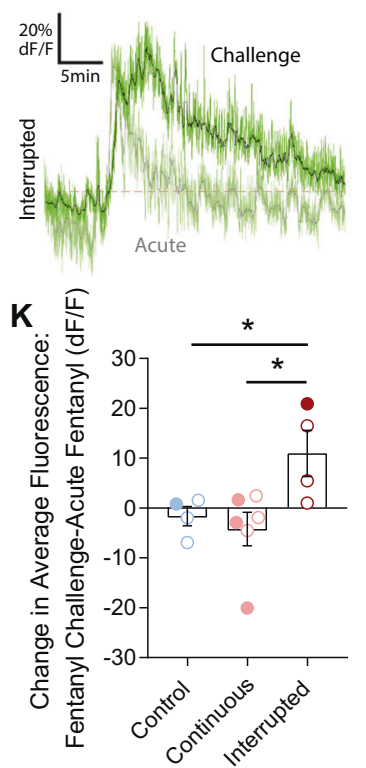

Mesolimbic dopamine signaling after continuous versus interrupted morphine exposure

To determine whether these divergent behavioral changes are associated with different patterns of dopamine signaling in the nucleus accumbens, we used fiber photometry to measure fluorescent signals from a genetically encoded dopamine sensor, dLight 1.3b [57, 58]. We stereotaxically injected adeno-associated virus (AAV) expressing dLight1.3b into the nucleus accumbens, followed by optic fiber implantation above the site of virus injection (Fig. 3a). This experiment included some DAT-IRES-Cre 
Fig. 3 Mesolimbic dopamine sensitization induced by interrupted morphine. a Stereotaxic injection of AAV1-Syn-dLight1.3b into the nucleus accumbens and AAVdj-Syn-FLEX-ChrimsonR into the VTA of DAT-IRES-Cre mice $(n=10)$. $\mathbf{b}$ Top panel: example of optic fiber implanted in the nucleus accumbens core, with local dLight expression (green) and ChrimsonR expression in dopamine axon terminals (red). Bottom panel: ChrimsonR expression in the VTA, with dopamine neurons labeled by tyrosine hydroxylase (Th) immunofluorescence. Scale bar $=$ $1 \mathrm{~mm}$. c Setup for simultaneous optogenetic stimulation $(595 \mathrm{~nm})$ and fiber photometry recording $(405 / 470 \mathrm{~nm})$. d Frequency-dependent changes in dLight fluorescent signal following optogenetic stimulation of ChrimsonR dopamine terminals in the nucleus accumbens. e Trace showing block of fluorescent signal by the D1 receptor antagonist SCH23390 (red arrow denotes s.c. injection). Inset: quantification of SCH23390 effects on average fluorescent signal (left) and transient event amplitude (right). $\mathbf{f}$ Experimental timeline for photometry recordings. g Examples of spontaneous fluorescent transients recorded on days 1 and 7 . $\mathbf{h}$ Average transient event amplitude on days 0 , 1, and 7 for Control, Continuous and Interrupted morphine treatment groups $\left(n=6-8 /\right.$ group). ${ }^{*} p<0.05$, Group $\times$ Day interaction. i Change in transient event size on D7 versus D1, depicted for individual mice. ${ }^{*} p<0.05$, LSD post-hoc test. $\mathbf{j}$ Representative trace showing the response to acute fentanyl (light green) and fentanyl challenge (dark green), for continuous morphine (top) and interrupted morphine (bottom). $\mathbf{k}$ Change in average fluorescent signal after fentanyl challenge, compared to acute fentanyl. ${ }^{*} p<0.05$, LSD post-hoc test; note that challenge data from six mice are missing due to lost head caps. All groups contained similar numbers of female mice (open symbols) and male mice (closed symbols); see Supplementary Table 2 for detailed statistical analyses.

knock-in mice, which received a second VTA injection of AAV expressing Cre-dependent ChrimsonR, a red-shifted excitatory opsin [59] (Fig. 3a). ChrimsonR was expressed by dopamine neurons in the VTA and transported to their axon terminals in nucleus accumbens (Fig. 3b). We delivered red light $(595 \mathrm{~nm})$ to stimulate dopamine release, and monitored dLight $1.3 \mathrm{~b}$ signal through the same optic fiber at both dopamine-dependent and control wavelengths $(470 / 405 \mathrm{~nm}$, respectively; Fig. 3c). To validate the correspondence between dLight1.3b fluorescence and dopamine signaling, we confirmed that the fluorescent signal increased with red-shifted optogenetic stimulation in a frequencydependent fashion (Fig. 3d), and was blocked by the D1 dopamine receptor antagonist SCH23390 (Fig. 3e).

We next conducted fiber photometry recordings the day prior to implantation of osmotic pumps, and on Days 1 and 7 of chronic morphine treatment (Fig. 3f). Naloxone injection significantly reduced fluorescent signals on both Days 1 and 7 in mice implanted with morphine pumps, but not mice implanted with saline pumps (Fig. S3C-F). There were no differences in fluorescent signals between mice implanted with saline pumps and injected with either saline or naloxone, so these groups were combined to form a single "control" group. To quantify changes in baseline dopamine dynamics, we used peak analysis to identify spontaneous fluorescent transient events [60], which were blocked by $\mathrm{SCH} 23390$ (Fig. 3e). The amplitude of these transient events was increased in both morphine groups prior to naloxone injection on Day 1, but then diverged on Day 7 (Fig. 3h; Group $\times$ Day interaction; $\mathrm{F}_{4,28}=5.20, p=0.006$ ). Event amplitude tended to decrease over the course of continuous morphine exposure, but tended to increase over the course of interrupted morphine exposure (Fig. 3i; main effect of Group: $\mathrm{F}_{2,14}=2.71, p=0.10$ ).

To examine the persistence of these changes in dopamine signaling, we administered a challenge injection of morphine ( $2 \mathrm{mg} / \mathrm{kg}$ ) one week after pump removal, a time point where interrupted morphine treatment caused locomotor sensitization (Fig. 2h). The interrupted morphine group showed an increase in average fluorescent signal after morphine challenge, which tended to be larger than either the control or continuous morphine group (Fig. S6). However, the change in fluorescent signal was modest and gradual, most likely because of morphine's slow pharmacokinetics relative to other opioids. These mice received an acute injection of fentanyl $(0.4 \mathrm{mg} / \mathrm{kg})$ prior to chronic morphine treatment (Day -1 ), which generated a rapid and robust signal similar to heroin [6], so we challenged them with the same dose of fentanyl one day after morphine challenge (Fig. 3j). The interrupted morphine group showed a significant enhancement in the response to fentanyl challenge, compared to acute fentanyl injection (Fig. 3k; main effect of Group: $F_{2,8}=6.23, p=$ 0.023). Overall, these data provide convergent evidence for persistent sensitization of the mesolimbic dopamine system following interrupted morphine exposure.
Differential gene expression after continuous versus interrupted morphine exposure

We next assessed the downstream consequences of continuous and interrupted morphine exposure on gene expression in the nucleus accumbens. To minimize variability related to sex differences, we used only male mice in this experiment, since interrupted morphine caused more robust locomotor sensitization in males. At the end of chronic treatment, we dissected the nucleus accumbens as well as the dorsal striatum (Fig. 4a), and used next-generation RNA sequencing to perform genome-wide transcriptional profiling. We defined differential gene expression with a fold change threshold of $15 \%$, while controlling false discovery rate at $q<0.05$. With these criteria, there was no evidence of differential gene expression between saline-saline and saline-naloxone treatments (Table S3), so these treatments were combined to form a single "control" group.

Compared to the control group, interrupted morphine significantly regulated 687 transcripts in the nucleus accumbens and 407 transcripts in the dorsal striatum (Fig. 4b-d). Surprisingly, continuous morphine significantly regulated only one gene (Sst) in the dorsal striatum. With a less stringent statistical threshold of $p<0.05$, continuous morphine significantly regulated 112 genes in the nucleus accumbens and 294 genes in the dorsal striatum (Fig. S7), comparable to previous studies of chronic morphine exposure [61, 62]. Interrupted morphine still had substantially greater impact, significantly regulating 1389 and 1382 genes in the nucleus accumbens and dorsal striatum, respectively. Using our original statistical criteria $(q<0.05)$, direct comparison of continuous and interrupted morphine (Fig. 4b) also revealed differential gene expression in both the nucleus accumbens (84 transcripts) and dorsal striatum (111 transcripts).

In both the nucleus accumbens and dorsal striatum (Fig. 4e-h), there was a high degree of similarity in the effect of interrupted morphine compared to either continuous morphine or control (Fig. S8). There were no significant changes in expression of opioid or dopamine receptors, but a number of downstream signaling molecules showed significant regulation following interrupted morphine exposure: G-protein subunits (Gna11/Gnaz/Gnb2), regulators of G-protein signaling (Rgs2/Rgs11/Rgs20), adenylate cyclase (Adcy8), phosphodiesterase (Enpp6), and transcription factors (Creb1/Crebl2). Several of these genes have previously been shown to regulate responses to morphine [63-72]. Two of the most dramatic effects were downregulation of Rbm3 and Cirbp, which were previously reported to be downregulated in the nucleus accumbens following continuous morphine exposure [61]. We used quantitative RT-PCR to validate these changes in tissue from an independent cohort of male and female mice. In both nucleus accumbens and dorsal striatum, Rbm3 and Cirbp expression was decreased after continuous morphine and further reduced by interrupted morphine (Fig. $4 \mathrm{i}-\mathrm{I}$ ). We also validated the upregulation of two heat shock proteins, Hspb1 and Hspa5, after interrupted morphine exposure (Fig. $4 \mathrm{~m}-\mathrm{p}$ ). 
A

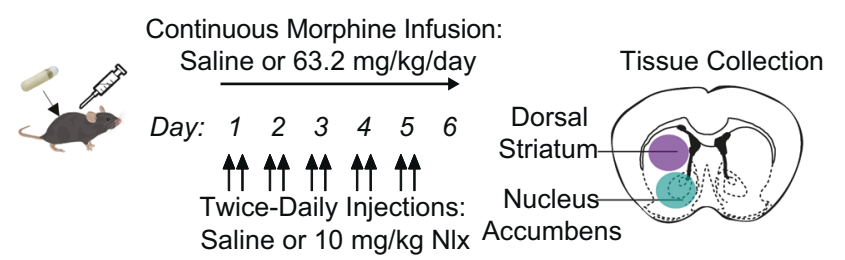

B Nucleus Accumbens

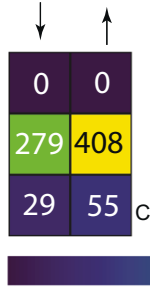

Nucleus Accumbens

C

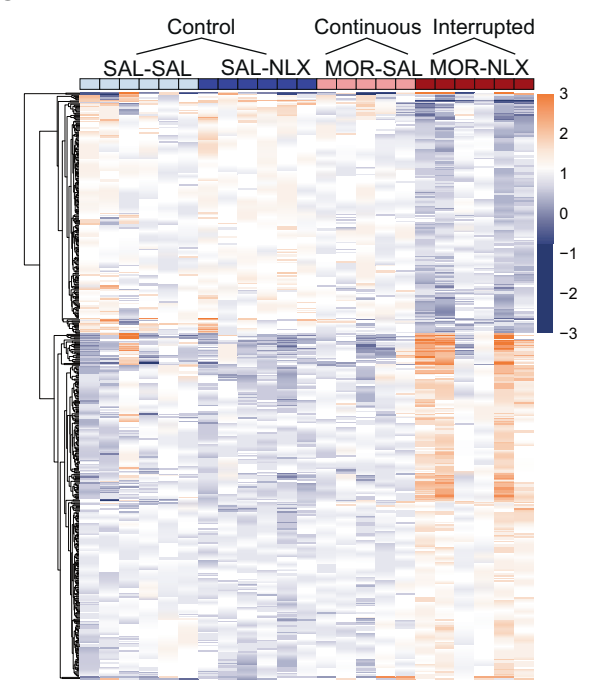

$\mathbf{E}$

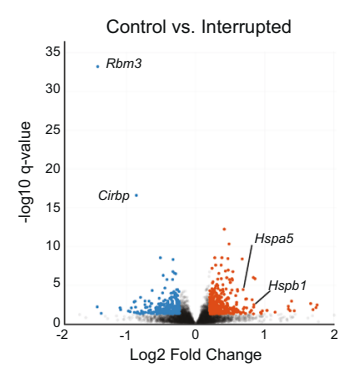

F

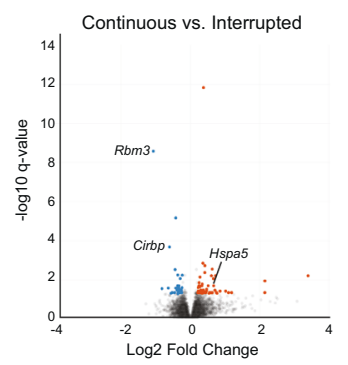

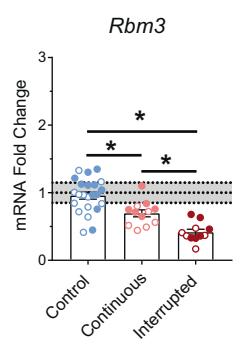

J

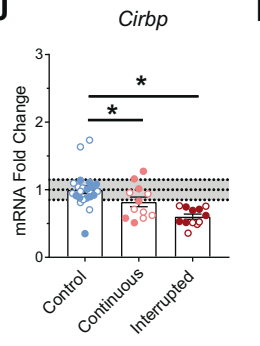

M

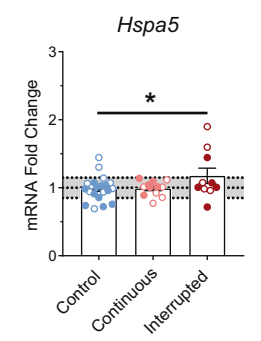

$\mathbf{N}$

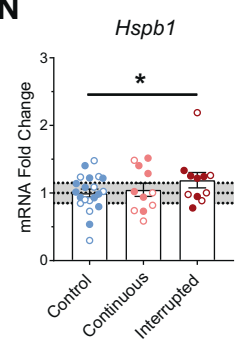

Dorsal Striatum

D

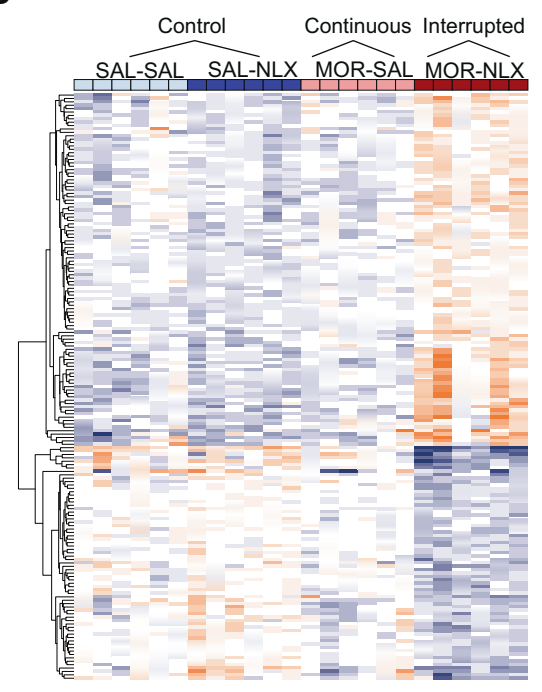

G

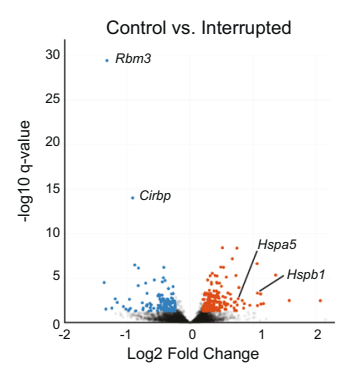

H

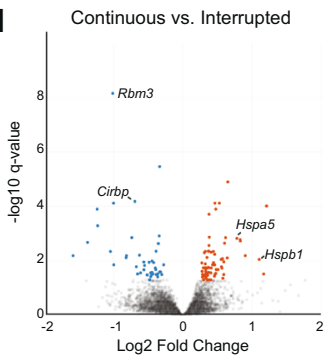

K

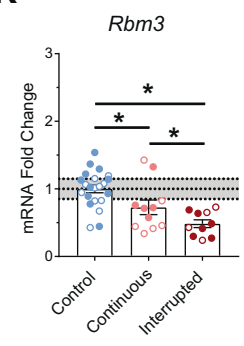

$\mathbf{L}$

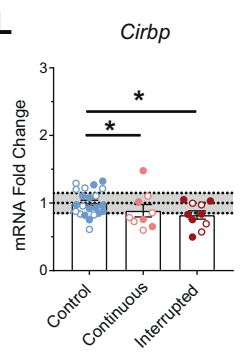

Dorsal Striatum

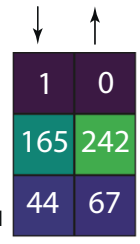

Increasing number of genes 
Fig. 4 Differential gene expression after continuous or interrupted morphine. a Microdissection of nucleus accumbens or dorsal striatum tissue for RNA sequencing after 6 days of continuous or interrupted morphine exposure ( $n=5-6$ male mice/group). b The number of differentially expressed genes (DEGs) that were significantly up- or down-regulated in each brain region; note that mice implanted with saline pumps have been combined to form a single control group. $\mathbf{c}$, $\mathbf{d}$ Heat maps showing normalized level of DEGs for each individual sample in the nucleus accumbens (c) and dorsal striatum (d). e-h Volcano plots of significantly up- and down-regulated genes after interrupted morphine in the nucleus accumbens $(\mathbf{e}, \mathbf{f})$ and dorsal striatum $(\mathbf{g}, \mathbf{h})$. Highlighted are cold-shock proteins Rbm3 (RNA binding motif protein 3 ) and Cirbp (cold inducible RNA binding protein) and heat-shock proteins Hspb1 and Hspa5. i-p Independent validation of highlighted genes with quantitative RT-PCR. Shaded area shows the $15 \%$ fold change threshold used to define differential gene expression in RNA sequencing data ( $n=10-24 /$ group), with similar numbers of female mice (open symbols) and male mice (closed symbols) for PCR validation; see Supplemental Table S2 for detailed statistical analyses. ${ }^{*} p<0.05$, LSD post-hoc test.

both striatal subregions (Fig. 5a, b). The majority of individual molecules driving significant changes in these pathways were heat shock proteins (Table S4). In comparison to both control and continuous morphine, interrupted morphine upregulated transcripts encoding numerous individual heat shock proteins in the nucleus accumbens and dorsal striatum (Fig. S9). Significant changes in two top upstream regulators, heat shock transcription factor 1 (HSF1) and sphingosine-1-phosphate phosphatase 2 (SGPP2), were also driven primarily by heat shock proteins (Table S5).

We further analyzed RNA sequencing data using weighted gene co-expression network analysis (WGCNA), a computational method that does not require binary thresholds for differential gene expression [73]. We identified 18 consensus modules that exhibited correlated patterns of expression across samples and treatment conditions, which were given arbitrary color names (Fig. S10A). The magenta module showed significant regulation in both nucleus accumbens and dorsal striatum, while the turquoise and lime modules were only significantly regulated in the nucleus accumbens (Fig. S10B-E). We generated connectivity diagrams to visualize "hub" genes with the highest degree of connectivity within each module (Fig. 5c-e and Table S6).

Hub genes in the magenta module included Cirbp and Rbm3, and the two hub genes with greatest connectivity were heat shock proteins, Hspa5 and Hspa8 (Fig. 5e). Many of the same canonical pathways and upstream regulators detected in our analysis of differentially expressed genes were also represented in the magenta module (Fig. 5f). The turquoise and lime modules (Fig. 5g, h) implicated additional signaling pathways in the nucleus accumbens, including upregulation of FAK and actin cytoskeleton signaling (turquoise module) [74], as well as downregulation of signaling by Rho family GTPases (lime module). These results provide convergent evidence that interruption of continuous morphine exposure exacerbates drug-evoked changes in striatal gene expression, engaging novel signaling pathways that may contribute to opioid abuse and addiction.

\section{DISCUSSION}

Our data provide clear evidence that the pattern of opioid administration dictates drug-evoked adaptations in the mesolimbic dopamine system. Using psychomotor activity as a behavioral readout [75], we first replicated prior work showing robust psychomotor sensitization after intermittent morphine injections [39-43], while continuous morphine infusion caused psychomotor tolerance. The interruption of continuous opioid receptor stimulation with either spontaneous or naloxone-precipitated withdrawal caused a behavioral reversal of psychomotor tolerance. This behavioral switch was associated with enhancements of both dopamine signaling and gene expression in the nucleus accumbens, highlighting the fundamental influence of exposure pattern on opioid-evoked adaptations in this brain region.

Behavioral and neurochemical sensitization after interrupted morphine exposure

The neurobehavioral impact of chronic opioid exposure has been investigated in rodents using a wide variety of drug administration regimens. Our data confirm that daily morphine injections at a fixed dose cause psychomotor sensitization, whereas psychomotor tolerance is observed following either continuous exposure or multiple daily injections at escalating doses [39-43]. These patterns differ in the degree to which drug effects dissipate between each administration, and thus the cumulative amount of withdrawal that occurs over the course of chronic opioid administration. Periods of withdrawal between intermittent opioid exposure may represent a form of stress [46], leading to adverse consequences that can be avoided through sustained opioid receptor activation [48], including methadone maintenance therapy [45].

We used two strategies to interrupt continuous morphine administration, while simultaneously maintaining control of critical pharmacokinetic variables like cumulative dose and peak drug level. The first was a pharmacodynamic manipulation involving daily administration of naloxone to precipitate a state of withdrawal [51], which also represents a form of stress. The second was a pharmacokinetic manipulation, using miniaturized programmable infusion pumps to periodically shut off drug delivery and produce a state of spontaneous withdrawal. Both manipulations completely reversed the development of psychomotor tolerance normally caused by continuous morphine exposure. The psychomotor sensitization that developed after interrupting morphine exposure with naloxone persisted for weeks to months, mirroring the durable sensitization produced by intermittent morphine injections [76, 77], and contrasting with the transient nature of psychomotor tolerance $[78,79]$.

The persistence of psychomotor sensitization reflects longlasting adaptations in nucleus accumbens dopamine and glutamate signaling [75], which also enhance the incentive properties of drugs and associated cues [80]. To measure dynamic changes in nucleus accumbens dopamine signaling, we used fiber photometry to monitor fluorescent signals from a genetically encoded dopamine sensor, dLight $1.3 b$ [57, 58]. The amplitude of spontaneous fluorescent transients increased in parallel with the development of psychomotor sensitization during interrupted morphine exposure, similar to changes detected using fast-scan cyclic voltammetry following cocaine exposure [81]. One week after interrupted morphine exposure, we also detected an enhanced dopamine response to challenge injection of fentanyl. These data are consistent with enhanced mesolimbic dopamine release reported after intermittent morphine exposure $[29,30]$, and contrast with reduced dopamine release following continuous morphine exposure [31]. These effects on dopamine release may contribute to the respective sensitization and tolerance of drug reward following intermittent and continuous opioid exposure [32-38], although further research is needed to determine whether interrupted opioid exposure increases subsequent sensitivity to opioid reward.

Nucleus accumbens gene expression after interrupted morphine exposure

The distinct behavioral effects of continuous and interrupted morphine exposure were mirrored at the level of gene expression in the nucleus accumbens and dorsal striatum. In both brain regions, the number of differentially expressed transcripts was substantially 
A

Control vs. Interrupted

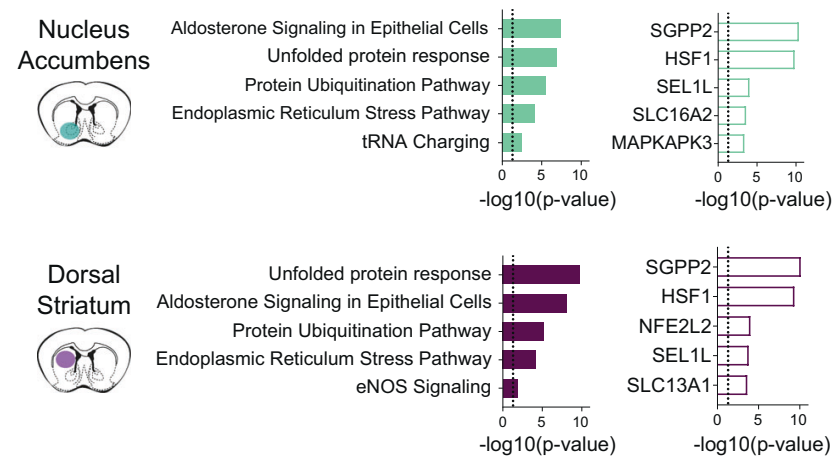

\section{Continuous vs. Interrupted}
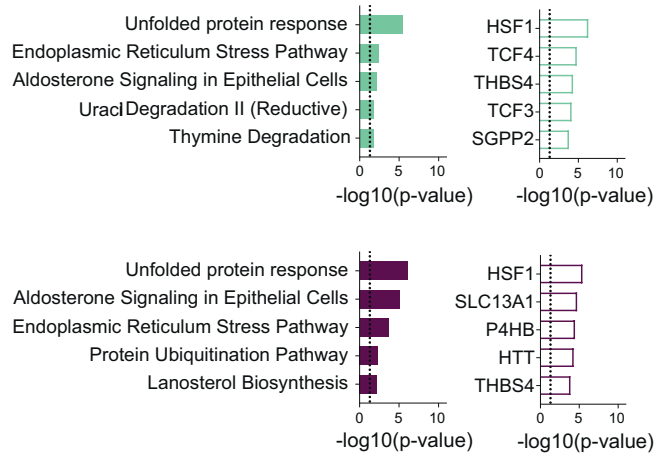

\section{WEIGHTED GENE CO-EXPRESSION NETWORK ANALYSIS}

(all genes)

C

Magenta Hub Genes

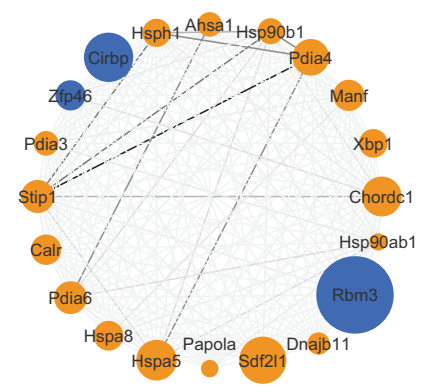

$\mathbf{F}$
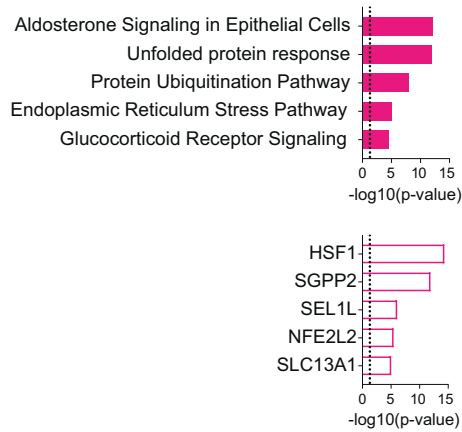

D

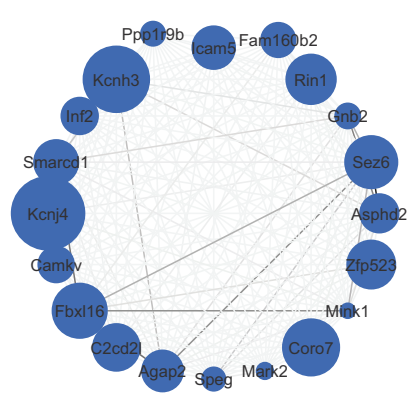

G
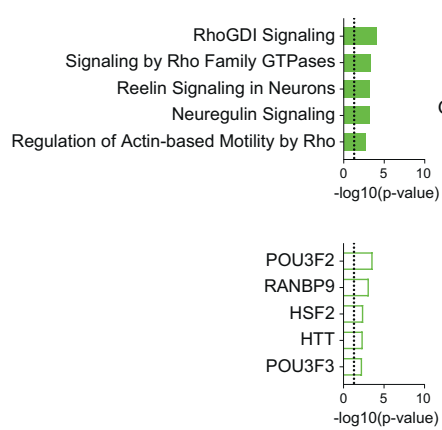

E

\section{Turquoise Hub Genes}

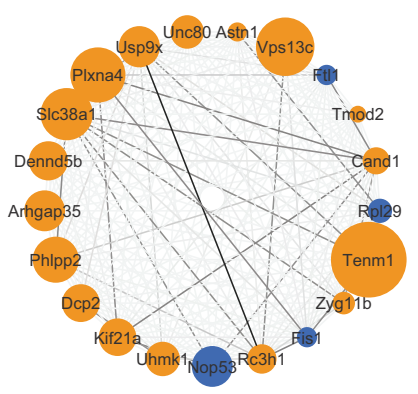

H

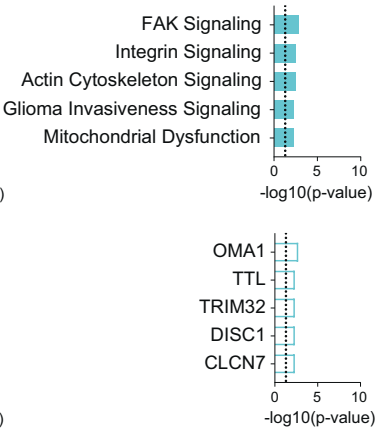

Fig. 5 Characterization of differentially expressed genes. a, b Top five canonical pathways (closed bar) and upstream regulators (open bars) identified by Ingenuity Pathway Analysis for interrupted morphine versus control (a) or continuous morphine (b), in the nucleus accumbens (top row) and dorsal striatum (bottom row). Dotted line on bar graphs indicates $p=0.05$; for details regarding drug treatment, refer Fig. 4 ( $n=$ 5-12 male mice/group). c-e Weighted gene co-expression network analysis identified three consensus modules across the nucleus accumbens and dorsal striatum: magenta (c), lime (d) and turquoise (e). Top 20 hub genes with the highest degree of connectivity are displayed for each module, with node size scaled by fold change in the control vs. interrupted morphine comparison, and node color indicating upregulation (orange) or downregulation (blue). The weight of edges connecting nodes is scaled such that stronger connections are darker in color. f-h Ingenuity Pathway Analysis of canonical pathways (top row) and upstream regulators (bottom row) for genes in the magenta module (f), lime module (g), and turquoise module (h).

greater after interrupted versus continuous morphine. Continuous morphine regulated $100-200$ genes by conventional statistical standards $(p<0.05)$, similar to previous reports [61], but only a single gene reached statistical criteria for differential expression after controlling for false discovery rate $(q<0.05)$. The impact of continuous morphine on striatal gene expression is thus less severe than interrupted morphine, as previously reported for chronic morphine treatment and morphine withdrawal in other brain regions [82]. Naloxone injection did not significantly alter gene expression in control mice implanted with saline pumps, most likely because tissue was collected $24 \mathrm{~h}$ after the last naloxone injection, permitting time for transcriptional recovery after naloxone injection in the absence of morphine.

Individual genes involved in opioid and dopamine receptor signaling were differentially regulated by interrupted morphine exposure, although Ingenuity Pathway Analysis did not reveal 
significant enrichment of these canonical pathways (which are not specifically tailored to genes with enriched expression in striatal tissue). The changes in nucleus accumbens dopamine signaling we report may begin with alterations in dopamine cell bodies in the VTA [31, 36], which subsequently impact striatal gene expression. A number of genes that were differentially expressed after interrupted morphine encode synaptic receptors for glutamate (Gria4, Grin2d, Grin3a), GABA (Gabra2, Gabrb2), and glycine (Glra2, Glra3). This is consistent with well-established effects of chronic drug exposure on synaptic transmission in the nucleus accumbens [10], including opioid-evoked plasticity at excitatory and inhibitory synapses [83-85]. Intermittent morphine injections also increase expression of glutamate receptor subunits in the nucleus accumbens [86]. The upregulation of Gabra2 we observe following interrupted morphine contrasts with the downregulation previously reported in the nucleus accumbens after continuous morphine [85], further highlighting the differential impact of these two patterns of exposure.

Ingenuity pathway analysis of either differentially expressed gene lists or the WCGNA magenta module identified similar canonical pathways, including unfolded protein response and endoplasmic reticulum stress. Interrupted morphine exposure upregulated many genes encoding heat shock proteins while robustly reducing expression of two cold shock proteins, Rbm3 and Cirbp. Changes in expression of both heat and cold shock proteins have previously been reported in striatal tissue following opioid treatment $[61,87-91]$, and our quantitative RT-PCR analysis shows that changes in expression of these genes are exacerbated by the interruption of continuous morphine exposure with naloxone. These gene expression changes could be related to opioid-induced temperature fluctuations in the nucleus accumbens [92], or a more general response to cellular stress that is independent of temperature. Striatal expression of heat shock proteins is tied to psychomotor sensitization, withdrawal, and other behavioral responses to opioids [89, 93-98], supporting functional relevance of the transcriptional changes we observe. As a top upstream transcriptional regulator, HSF1 is a novel and intriguing therapeutic target for addiction that also plays a role in cancer and neurodegenerative disease [99].

In conclusion, our data show that interruption of continuous opioid administration sensitizes mesolimbic dopamine transmission and exacerbates transcriptional changes in the nucleus accumbens and dorsal striatum, producing an enhanced behavioral sensitivity to opioids that persists for months. Maintaining the continuity of chronic opioid administration may, therefore, represent a strategy to minimize iatrogenic effects on brain reward circuits [13], preventing sensitization of the mesolimbic dopamine system that could otherwise increase vulnerability to subsequent opioid abuse and addiction.

\section{FUNDING AND DISCLOSURE}

Research reported in this publication was supported by the University of Minnesota's MnDRIVE (Minnesota's Discovery, Research and Innovation Economy) initiative (to EML, MTP, and PER), as well as a grants from the University of Minnesota Medical Discovery Team on Addiction (PER), MQ: Transforming Mental Health through Research (PER) and the National Institutes of Health: MH118794 (MTP), DA007234 (CT), DA048946 (PER), and DA037279 (PER). The authors declare no competing interests.

\section{ACKNOWLEDGEMENTS}

We thank Kerry Trotter, David Leipold, and Lauren Bystrom for technical assistance, as well as Brian Trieu, Dieter Brandner, and Drs. Cassandra Retzlaff and Rocio GomezPastor for stimulating discussions. Some of the viral vectors used in this study were generated by the University of Minnesota Viral Vector and Cloning Core. The University of Minnesota MnDRIVE Optogenetics Core provided technical support for fiber photometry experiments. The University of Minnesota Genomics Center conducted RNA sequencing, and the Minnesota Supercomputing Institute (MSI) at the University of Minnesota provided resources that contributed to the research results reported within this paper.

\section{ADDITIONAL INFORMATION}

Supplementary Information accompanies this paper at (https://doi.org/10.1038/ s41386-020-0643-x).

Publisher's note Springer Nature remains neutral with regard to jurisdictional claims in published maps and institutional affiliations.

\section{REFERENCES}

1. Valentino RJ, Volkow ND. Untangling the complexity of opioid receptor function. Neuropsychopharmacol. 2018;43:2514-20.

2. Darcq E, Kieffer BL. Opioid receptors: drivers to addiction? Nat Rev Neurosci. 2018;19:499-514.

3. David V, Matifas A, Gavello-Baudy S, Decorte L, Kieffer BL, Cazala P. Brain regional Fos expression elicited by the activation of mu- but not delta-opioid receptors of the ventral tegmental area: evidence for an implication of the ventral thalamus in opiate reward. Neuropsychopharmacol. 2008;33:1746-59.

4. Olds ME. Reinforcing effects of morphine in the nucleus accumbens. Brain Res. 1982;237:429-40.

5. Di Chiara G, Imperato A. Drugs abused by humans preferentially increase synaptic dopamine concentrations in the mesolimbic system of freely moving rats. Proc Natl Acad Sci USA. 1988;85:5274-8.

6. Corre J, van Zessen R, Loureiro M, Patriarchi T, Tian L, Pascoli V, et al. Dopamine neurons projecting to medial shell of the nucleus accumbens drive heroin reinforcement. Elife. 2018;7:e39945.

7. Nutt DJ, Lingford-Hughes A, Erritzoe D, Stokes PR. The dopamine theory of addiction: 40 years of highs and lows. Nat Rev Neurosci. 2015;16:305-12.

8. Spagnolo PA, Kimes A, Schwandt ML, Shokri-Kojori E, Thada S, Phillips KA, et al. Striatal dopamine release in response to morphine: a $[(11) C]$ raclopride positron emission tomography study in healthy men. Biol Psychiatry 2019;86:356-64.

9. Badiani A, Belin D, Epstein D, Calu D, Shaham Y. Opiate versus psychostimulant addiction: the differences do matter. Nat Rev Neurosci. 2011;12:685-700.

10. Nestler EJ, Luscher C. The molecular basis of drug addiction: linking epigenetic to synaptic and circuit mechanisms. Neuron. 2019;102:48-59.

11. Reiner DJ, Fredriksson I, Lofaro OM, Bossert JM, Shaham Y. Relapse to opioid seeking in rat models: behavior, pharmacology and circuits. Neuropsychopharmacol. 2019;44:465-77.

12. Kruyer A, Chioma VC, Kalivas PW. The opioid-addicted tetrapartite synapse. Biol Psychiatry 2020;87:34-43.

13. Peltz G, Sudhof TC. The neurobiology of opioid addiction and the potential for prevention strategies. JAMA. 2018;319:2071-72.

14. Nelson LR, Ellison G. Enhanced stereotypies after repeated injections but not continuous amphetamines. Neuropharmacology. 1978;17:1081-4.

15. Reith ME, Benuck M, Lajtha A. Cocaine disposition in the brain after continuous or intermittent treatment and locomotor stimulation in mice. J Pharm Exp Ther. 1987;243:281-7.

16. King GR, Joyner C, Lee T, Kuhn C, Ellinwood EH Jr. Intermittent and continuous cocaine administration: residual behavioral states during withdrawal. Pharm Biochem Behav. 1992:43:243-8.

17. Gao WY, Lee TH, King GR, Ellinwood EH. Alterations in baseline activity and quinpirole sensitivity in putative dopamine neurons in the substantia nigra and ventral tegmental area after withdrawal from cocaine pretreatment. Neuropsychopharmacol. 1998;18:222-32.

18. Breese GR, Knapp DJ, Overstreet DH. Stress sensitization of ethanol withdrawalinduced reduction in social interaction: inhibition by CRF-1 and benzodiazepine receptor antagonists and a 5-HT1A-receptor agonist. Neuropsychopharmacol. 2004;29:470-82.

19. Hope BT, Crombag HS, Jedynak JP, Wise RA. Neuroadaptations of total levels of adenylate cyclase, protein kinase A, tyrosine hydroxylase, cdk5 and neurofilaments in the nucleus accumbens and ventral tegmental area do not correlate with expression of sensitized or tolerant locomotor responses to cocaine. J Neurochem. 2005;92:536-45.

20. Zimmer BA, Oleson EB, Roberts DC. The motivation to self-administer is increased after a history of spiking brain levels of cocaine. Neuropsychopharmacol. 2012;37:1901-10.

21. Calipari ES, Ferris MJ, Zimmer BA, Roberts DC, Jones SR. Temporal pattern of cocaine intake determines tolerance vs sensitization of cocaine effects at the dopamine transporter. Neuropsychopharmacol. 2013;38:2385-92. 
22. Calipari ES, Siciliano CA, Zimmer BA, Jones SR. Brief intermittent cocaine selfadministration and abstinence sensitizes cocaine effects on the dopamine transporter and increases drug seeking. Neuropsychopharmacol. 2015;40:728-35.

23. Allain F, Samaha AN. Revisiting long-access versus short-access cocaine selfadministration in rats: intermittent intake promotes addiction symptoms independent of session length. Addict Biol. 2019;24:641-51.

24. Nicolas C, Russell TI, Pierce AF, Maldera S, Holley A, You ZB, et al. Incubation of cocaine craving after intermittent-access self-administration: sex differences and estrous Cycle. Biol Psychiatry. 2019;85:915-24.

25. Kawa $A B$, Valenta $A C$, Kennedy RT, Robinson TE. Incentive and dopamine sensitization produced by intermittent but not long access cocaine selfadministration. Eur J Neurosci. 2019;50:2663-82.

26. Post RM. Intermittent versus continuous stimulation: effect of time interval on the development of sensitization or tolerance. Life Sci. 1980;26:1275-82.

27. Marie N, Canestrelli C, Noble F. Role of pharmacokinetic and pharmacodynamic parameters in neuroadaptations induced by drugs of abuse, with a focus on opioids and psychostimulants. Neurosci Biobehav Rev. 2019;106:217-26.

28. Kawa $A B$, Allain $F$, Robinson $T E$, Samaha AN. The transition to cocaine addiction: the importance of pharmacokinetics for preclinical models. Psychopharmacol (Berl). 2019;236:1145-57.

29. Spanagel R, Almeida OF, Shippenberg TS. Long lasting changes in morphineinduced mesolimbic dopamine release after chronic morphine exposure. Synapse 1993;14:243-5.

30. Nestby P, Vanderschuren LJ, De Vries TJ, Hogenboom F, Wardeh G, Mulder AH, et al. Ethanol, like psychostimulants and morphine, causes long-lasting hyperreactivity of dopamine and acetylcholine neurons of rat nucleus accumbens: possible role in behavioural sensitization. Psychopharmacol (Berl). 1997;133:69-76.

31. Mazei-Robison MS, Koo JW, Friedman AK, Lansink CS, Robison AJ, Vinish M, et al. Role for mTOR signaling and neuronal activity in morphine-induced adaptations in ventral tegmental area dopamine neurons. Neuron. 2011;72:977-90.

32. Shippenberg TS, Emmett-Oglesby MW, Ayesta FJ, Herz A. Tolerance and selective cross-tolerance to the motivational effects of opioids. Psychopharmacol (Berl). 1988;96:110-5.

33. Lett BT. Repeated exposures intensify rather than diminish the rewarding effects of amphetamine, morphine, and cocaine. Psychopharmacol (Berl). 1989; 98:357-62.

34. Gaiardi M, Bartoletti M, Bacchi A, Gubellini C, Costa M, Babbini M. Role of repeated exposure to morphine in determining its affective properties: place and taste conditioning studies in rats. Psychopharmacol (Berl). 1991;103:183-6.

35. Shippenberg TS, Heidbreder C, Lefevour A. Sensitization to the conditioned rewarding effects of morphine: pharmacology and temporal characteristics. Eur J Pharm. 1996;299:33-9.

36. Russo SJ, Bolanos CA, Theobald DE, DeCarolis NA, Renthal W, Kumar A, et al. IRS2Akt pathway in midbrain dopamine neurons regulates behavioral and cellular responses to opiates. Nat Neurosci. 2007;10:93-9.

37. Sun L, Hu L, Li Y, Cui C. Mesoaccumbens dopamine signaling alteration underlies behavioral transition from tolerance to sensitization to morphine rewarding properties during morphine withdrawal. Brain Struct Funct. 2014;219:1755-71.

38. Yu G, Zhang FQ, Tang SE, Lai MJ, Su RB, Gong ZH. Continuous infusion versus intermittent bolus dosing of morphine: A comparison of analgesia, tolerance, and subsequent voluntary morphine intake. J Psychiatr Res. 2014;59:161-66.

39. Vanderschuren $L$, Tjon $G H$, Nestby $P$, Mulder $A H$, Schoffelmeer AN, De Vries TJ. Morphine-induced long-term sensitization to the locomotor effects of morphine and amphetamine depends on the temporal pattern of the pretreatment regimen. Psychopharmacol (Berl). 1997;131:115-22.

40. Eitan S, Bryant CD, Saliminejad N, Yang YC, Vojdani E, Keith D Jr., et al. Brain region-specific mechanisms for acute morphine-induced mitogen-activated protein kinase modulation and distinct patterns of activation during analgesic tolerance and locomotor sensitization. J Neurosci 2003;23:8360-9.

41. Contet C, Filliol D, Matifas A, Kieffer BL. Morphine-induced analgesic tolerance, locomotor sensitization and physical dependence do not require modification of mu opioid receptor, cdk5 and adenylate cyclase activity. Neuropharmacology. 2008;54:475-86.

42. Rothwell PE, Gewirtz JC, Thomas MJ. Episodic withdrawal promotes psychomotor sensitization to morphine. Neuropsychopharmacol. 2010;35:2579-89.

43. Le Marec T, Marie-Claire C, Noble F, Marie N. Chronic and intermittent morphine treatment differently regulates opioid and dopamine systems: a role in locomotor sensitization. Psychopharmacol (Berl). 2011;216:297-303.

44. Ackerman SJ, Mordin M, Reblando J, Xu X, Schein J, Vallow S, et al. Patientreported utilization patterns of fentanyl transdermal system and oxycodone hydrochloride controlled-release among patients with chronic nonmalignant pain. J Manag Care Pharm. 2003;9:223-31.

45. Dole VP, Nyswander ME, Kreek MJ. Narcotic blockade. Arch Intern Med. $1966 ; 118: 304-9$
46. Houshyar H, Gomez F, Manalo S, Bhargava A, Dallman MF. Intermittent morphine administration induces dependence and is a chronic stressor in rats. Neuropsychopharmacol. 2003;28:1960-72.

47. Evans CJ, Cahill CM. Neurobiology of opioid dependence in creating addiction vulnerability. F1000Res. 2016;5:1748.

48. Lee K, Vuong HE, Nusbaum DJ, Hsiao EY, Evans CJ, Taylor AMW. The gut microbiota mediates reward and sensory responses associated with regimenselective morphine dependence. Neuropsychopharmacol. 2018;43:2606-14.

49. Matthes HW, Maldonado R, Simonin F, Valverde O, Slowe S, Kitchen I, et al. Loss of morphine-induced analgesia, reward effect and withdrawal symptoms in mice lacking the mu-opioid-receptor gene. Nature. 1996;383:819-23.

50. Backman CM, Malik N, Zhang Y, Shan L, Grinberg A, Hoffer BJ, et al. Characterization of a mouse strain expressing Cre recombinase from the $3^{\prime}$ untranslated region of the dopamine transporter locus. Genesis. 2006;44:383-90.

51. Lichtblau L, Sparber SB. Opiate withdrawal in utero increases neonatal morbidity in the rat. Science. 1981;212:943-5.

52. Pravetoni M, Le Naour M, Harmon TM, Tucker AM, Portoghese PS, Pentel PR. An Oxycodone conjugate vaccine elicits drug-specific antibodies that reduce oxycodone distribution to brain and hot-plate analgesia. J Pharm Exp Ther. 2012;341:225-32.

53. Baruffaldi F, Kelcher AH, Laudenbach M, Gradinati V, Limkar A, Roslawski M, et al. Preclinical efficacy and characterization of candidate vaccines for treatment of opioid use disorders using clinically viable carrier proteins. Mol Pharm. 2018; 15:4947-62.

54. Pisansky MT, Lefevre EM, Retzlaff CL, Trieu BH, Leipold DW, Rothwell PE. Nucleus accumbens fast-spiking interneurons constrain impulsive action. Biol Psychiatry. 2019;86:836-47.

55. Calipari ES, Bagot RC, Purushothaman I, Davidson TJ, Yorgason JT, Pena CJ, et al. In vivo imaging identifies temporal signature of D1 and D2 medium spiny neurons in cocaine reward. Proc Natl Acad Sci USA. 2016;113:2726-31.

56. Cui Y, Ostlund SB, James AS, Park CS, Ge W, Roberts KW, et al. Targeted expression of mu-opioid receptors in a subset of striatal direct-pathway neurons restores opiate reward. Nat Neurosci. 2014;17:254-61.

57. Patriarchi T, Cho JR, Merten K, Howe MW, Marley A, Xiong WH, et al. Ultrafast neuronal imaging of dopamine dynamics with designed genetically encoded sensors. Science. 2018;360:eaat4422.

58. Mohebi A, Pettibone JR, Hamid AA, Wong JT, Vinson LT, Patriarchi T, et al. Dissociable dopamine dynamics for learning and motivation. Nature. 2019;570:65-70.

59. Klapoetke NC, Murata Y, Kim SS, Pulver SR, Birdsey-Benson A, Cho YK, et al. Independent optical excitation of distinct neural populations. Nat Methods. 2014;11:338-46.

60. Robinson JE, Coughlin GM, Hori AM, Cho JR, Mackey ED, Turan Z, et al. Optical dopamine monitoring with dLight1 reveals mesolimbic phenotypes in a mouse model of neurofibromatosis type 1. Elife. 2019;8:e48983.

61. Koo JW, Mazei-Robison MS, Chaudhury D, Juarez B, LaPlant Q, Ferguson D, et al BDNF is a negative modulator of morphine action. Science. 2012;338:124-28.

62. Skupio U, Sikora M, Korostynski M, Wawrzczak-Bargiela A, Piechota M, Ficek J, et al. Behavioral and transcriptional patterns of protracted opioid selfadministration in mice. Addict Biol. 2017;22:1802-16.

63. Maldonado R, Blendy JA, Tzavara E, Gass P, Roques BP, Hanoune J, et al. Reduction of morphine abstinence in mice with a mutation in the gene encoding CREB. Science. 1996:273:657-9.

64. Barrot M, Olivier JD, Perrotti LI, DiLeone RJ, Berton O, Eisch AJ, et al. CREB activity in the nucleus accumbens shell controls gating of behavioral responses to emotional stimuli. Proc Natl Acad Sci USA. 2002;99:11435-40.

65. Garzon J, Lopez-Fando A, Sanchez-Blazquez P. The R7 subfamily of RGS proteins assists tachyphylaxis and acute tolerance at mu-opioid receptors. Neuropsychopharmacol. 2003;28:1983-90.

66. Leck KJ, Bartlett SE, Smith MT, Megirian D, Holgate J, Powell KL, et al. Deletion of guanine nucleotide binding protein alpha $z$ subunit in mice induces a gene dose dependent tolerance to morphine. Neuropharmacology. 2004;46:836-46.

67. Valverde O, Mantamadiotis T, Torrecilla M, Ugedo L, Pineda J, Bleckmann S, et al Modulation of anxiety-like behavior and morphine dependence in CREB-deficient mice. Neuropsychopharmacol. 2004;29:1122-33.

68. Lopez-Fando A, Rodriguez-Munoz M, Sanchez-Blazquez P, Garzon J. Expression of neural RGS-R7 and Gbeta5 proteins in response to acute and chronic morphine. Neuropsychopharmacol. 2005;30:99-110.

69. Walters CL, Godfrey M, Li X, Blendy JA. Alterations in morphine-induced reward, locomotor activity, and thermoregulation in CREB-deficient mice. Brain Res. 2005;1032:193-9.

70. Li S, Lee ML, Bruchas MR, Chan GC, Storm DR, Chavkin C. Calmodulin-stimulated adenylyl cyclase gene deletion affects morphine responses. Mol Pharmacol. 2006;70:1742-9.

71. Zachariou V, Liu R, LaPlant Q, Xiao G, Renthal W, Chan GC, et al. Distinct roles of adenylyl cyclases 1 and 8 in opiate dependence: behavioral, electrophysiological, and molecular studies. Biol Psychiatry 2008;63:1013-21. 
72. Gaspari S, Purushothaman I, Cogliani V, Sakloth F, Neve RL, Howland D, et al. Suppression of RGSz1 function optimizes the actions of opioid analgesics by mechanisms that involve the Wnt/beta-catenin pathway. Proc Natl Acad Sci USA. 2018;115:E2085-E94.

73. Zhang B, Horvath S. A general framework for weighted gene co-expression network analysis. Stat Appl Genet Mol Biol. 2005;4:Article17.

74. Marie-Claire C, Courtin C, Roques BP, Noble F. Cytoskeletal genes regulation by chronic morphine treatment in rat striatum. Neuropsychopharmacol. 2004; 29:2208-15.

75. Vanderschuren LJMJ, Kalivas PW. Alterations in dopaminergic and glutamatergic transmission in the induction and expression of behavioral sensitization: a critical review of preclinical studies. Psychopharmacology. 2000;151:99-120.

76. Babbini M, Gaiardi M, Bartoletti M. Persistence of chronic morphine effects upon activity in rats 8 months after ceasing the treatment. Neuropharmacology. 1975; 14:611-4.

77. Shuster L, Webster GW, Yu G. Increased running response to morphine in morphine-pretreated mice. J Pharm Exp Ther. 1975;192:64-7.

78. Bartoletti M, Gaiardi M, Gubellini G, Bacchi A, Babbini M. Long-term sensitization to the excitatory effects of morphine. A motility study in post-dependent rats. Neuropharmacology. 1983;22:1193-6.

79. Dalia AD, Norman MK, Tabet MR, Schlueter KT, Tsibulsky VL, Norman AB. Transient amelioration of the sensitization of cocaine-induced behaviors in rats by the induction of tolerance. Brain Res. 1998;797:29-34.

80. Robinson $\mathrm{TE}$, Berridge $\mathrm{KC}$. The neural basis of drug craving: an incentivesensitization theory of addiction. Brain Res Brain Res Rev. 1993;18:247-91.

81. Stuber GD, Roitman MF, Phillips PE, Carelli RM, Wightman RM. Rapid dopamine signaling in the nucleus accumbens during contingent and noncontingent cocaine administration. Neuropsychopharmacol. 2005;30:853-63.

82. McClung CA, Nestler EJ, Zachariou V. Regulation of gene expression by chronic morphine and morphine withdrawal in the locus ceruleus and ventral tegmental area. J Neurosci. 2005;25:6005-15.

83. Hearing MC, Jedynak J, Ebner SR, Ingebretson A, Asp AJ, Fischer RA, et al. Reversal of morphine-induced cell-type-specific synaptic plasticity in the nucleus accumbens shell blocks reinstatement. Proc Natl Acad Sci USA. 2016;113:757-62.

84. Graziane NM, Sun S, Wright WJ, Jang D, Liu Z, Huang YH, et al. Opposing mechanisms mediate morphine- and cocaine-induced generation of silent synapses. Nat Neurosci. 2016;19:915-25.

85. Koo JW, Lobo MK, Chaudhury D, Labonte B, Friedman A, Heller E, et al. Loss of BDNF signaling in DIR-expressing NAc neurons enhances morphine reward by reducing GABA Inhibition. Neuropsychopharmacol. 2014;39:2646-53.

86. Sun H, Maze I, Dietz DM, Scobie KN, Kennedy PJ, Damez-Werno D, et al. Morphine epigenomically regulates behavior through alterations in histone $\mathrm{H} 3$ lysine 9 dimethylation in the nucleus accumbens. J Neurosci. 2012;32:17454-64.
87. Abul-Husn NS, Annangudi SP, Ma'ayan A, Ramos-Ortolaza DL, Stockton SD, Gomes I, et al. Chronic morphine alters the presynaptic protein profile: identification of novel molecular targets using proteomics and network analysis. PLos ONE. 2011;6:e25535.

88. Ammon-Treiber S, Grecksch G, Stumm R, Riechert $U$, Tischmeyer $H$, Reichenauer A, et al. Rapid, transient, and dose-dependent expression of Hsp70 messenger RNA in the rat brain after morphine treatment. Cell Stress Chaperon. 2004;9:182-97.

89. Luo JA, Jing L, Qin WJ, Zhang M, Lawrence AJ, Chen F, et al. Transcription and protein synthesis inhibitors reduce the induction of behavioural sensitization to a single morphine exposure and regulate $\mathrm{Hsp} 70$ expression in the mouse nucleus accumbens. Int J Neuropsychoph. 2011;14:107-21.

90. Sanchis-Segura C, Lopez-Atalaya JP, Barco A. Selective boosting of transcriptional and behavioral responses to drugs of abuse by histone deacetylase inhibition. Neuropsychopharmacol. 2009;34:2642-54.

91. Avey D, Sankararaman S, Yim AKY, Barve R, Milbrandt J, Mitra RD. Single-Cell RNASeq Uncovers a Robust Transcriptional Response to Morphine by Glia. Cell Rep. 2018;24:3619-29 e4.

92. Solis E Jr., Afzal A, Kiyatkin EA. Opposing mechanisms underlying differential changes in brain oxygen and temperature induced by intravenous morphine. J Neurophysiol. 2018;120:2513-21.

93. Salas E, Bocos C, Del Castillo C, Perez-Garcia C, Morales L, Alguacil LF. Gene expression analysis of heat shock proteins in the nucleus accumbens of rats with different morphine seeking behaviours. Behav Brain Res. 2011;225:71-6.

94. Qin WJ, Wang YT, Zhang M, Wen RT, Liu Q, Li YL, et al. Molecular chaperone heat shock protein 70 participates in the labile phase of the development of behavioural sensitization induced by a single morphine exposure in mice. Int J Neuropsychoph. 2013;16:647-59.

95. Wang YT, Qin WJ, Liu Q, Li YL, Liang H, Chen F, et al. Chaperone heat shock protein 70 in nucleus accumbens core: a novel biological target of behavioural sensitization to morphine in rats. Int J Neuropsychoph. 2014;17:469-84.

96. Yang HY, Pu XP, Liu Y. Chronic morphine treatment induces over-expression of HSP70 in mice striatum related with abnormal ubiquitin-proteasome degradation. Drug Alcohol. Depend. 2014;139:53-9.

97. Qin WJ, Wang YT, Li PM, Wang XX, Li JX, Noori HR, et al. Context- and timedependent neurobiological and behavioral sensitization induced by a single morphine exposure in mice. Psychopharmacol (Berl). 2016;233:1147-55.

98. Luo FC, Qi L, Lv T, Wang SD, Liu H, Nakamura H, et al. Geranylgeranylacetone protects mice against morphine-induced hyperlocomotion, rewarding effect, and withdrawal syndrome. Free Radic Bio Med. 2012;52:1218-27.

99. Gomez-Pastor R, Burchfiel ET, Thiele DJ. Regulation of heat shock transcription factors and their roles in physiology and disease. Nat Rev Mol Cell Biol. 2018;19:4-19. 